\title{
Chemical Imaging of Microstructure of Chickpea Seed Tissue within a Cellular Dimension using Synchrotron Infrared Microspectroscopy: A Preliminary Study
}

\author{
Xin Feng \\ Virginia Tech https://orcid.org/0000-0002-3986-3714 \\ $\mathrm{Na}$ Liu \\ Canadian Light Source Inc \\ Peiqiang Yu ( $\sim$ peiqiang.yu@usask.ca ) \\ University of Saskatchewan
}

\section{Research}

Keywords: chickpea, microstructure, synchrotron, infrared microspectroscopy, chemical imaging

Posted Date: July 10th, 2020

DOl: https://doi.org/10.21203/rs.3.rs-40837/v1

License: (c) (i) This work is licensed under a Creative Commons Attribution 4.0 International License. Read Full License

Version of Record: A version of this preprint was published at Journal of Agricultural and Food Chemistry on September 18th, 2020. See the published version at https://doi.org/10.1021/acs.jafc.0c04446. 


\section{Abstract}

Background: Synchrotron radiation-based infrared microspectroscopy (SR-IMS) is a non-destructive bioanalytical technique with a high signal to noise ratio and high ultra-spatial resolution $(3-10 \mu \mathrm{m})$. It is capable to explore the microstructures of plant tissues in a chemical sense and provide information on the composition, structure, and distribution of chemical compounds/ functional groups. The objective of this study was to illustrate how the SR-IMS can be used to image the internal microstructures of chickpea seed tissue on a cellular level.

Methods: Chickpea seeds (CDC Cory) were collected from the Crop Development Center (University of Saskatchewan, Saskatoon, SK). The seed samples were frozen at $-20^{\circ} \mathrm{C}$ on the object disks in a cryostatic microtome and then were cut into thin cross sections (ca. $8 \mu \mathrm{m}$ thick). The experiment was carried out on the Mid-Infrared beamline (01B1-1) at the Canadian Light Source (Saskatoon, SK).

Results: We obtained the ultra-spatial images of chickpea tissue with pixel-sized increments of imaging steps. The results showed that with the extremely bright synchrotron light, spectra with high signal to noise ratios can be obtained from area as small as $3.3 \mu \mathrm{m}$ allowing us to observe the seed tissue within a cellular level. Chemical distribution of chickpea such as lipids, protein, and carbohydrates could be mapped, revealing the chemical information of chickpea internal microstructure.

Conclusions: In conclusion, SR-IMS can rapidly characterize molecular structure of protein, carbohydrates, and lipids at ultra-spatial resolution.

\section{Background}

Chickpea (Cicer arietinum L.), mainly cultivated in India, Pakistan, Iran, Australia and Turkey, is the third major pulse crop in the world after beans and peas. Due to the high protein content, legumes are consumed as food in many parts of the world (20-50\%) in comparison to other crops [1]. Chickpea is primarily used as human food in many areas of the word as a good source of protein (19-30\%), starch (33-44\%), and fiber. The protein quality of chickpea is considered to be superior compared to other grain legumes. Chickpea contains a variety of anti-nutritional compounds, such as protease and amylase inhibitors, lectins, polyphenols, and oligosaccharides which can impair nutrient absorption and affect human health and production. As the production of chickpea increase, those not suitable for human consumption are used as a high energy and protein feed in animal diets [2]. To increase the utilization efficiency of nonconventional feed ingredients such as chickpea as animal feed and the economic return, producing chickpea has been a growing interest in Canada largely fuelled by its profitability and export potential. Chickpea has been successfully incorporated into the diets for beef and dairy cattle as a partial replacement of soybean meal and cereal grains without any negative effect on diet digestibility and animal performance [3].

CDC Cory is a new chickpea variety cultivated by Crop Development Center (CDC) of University of Saskatchewan with high tolerance to solo ADV herbicide (imazamox herbicide). Limited information is 
available on the nutritional value of this newly developed chickpea variety as ruminant feed. The nutrient utilization, bioavailability, and feed quality are affected by the content and composition of its nutrients and also by the physical structure of molecules [4]. Research shows that intrinsic structure of protein largely affects ruminal degradation characteristics and post-ruminal availability of protein [5]. Therefore quantifying the inherent molecular structure is vital to fully understand the variation in nutrients digestibility and utilization in this new chickpea variety.

Synchrotron radiation based infrared microspectroscopy (SR-IMS) has been used to reveal molecular structural features of different kind of materials [6]. With the synchrotron light brightness (100-1000 times brighter than conventional globar source light), this technique is able to explore the molecular chemistry of biological samples with high signal to noise ratio at ultra-spatial resolution as fine as $3-10 \mu \mathrm{m}$ [7]. Without destructive effects on the intrinsic microstructures of plant tissue, SR-IMS can be used to detect information on ultra-structural chemistry by imaging or mapping within cellular dimension [8]. SR-IMS has been used to compare plant tissues (varieties) according to spectroscopic characteristics, functional groups, spatial distribution, and chemical intensity and also relate plant molecular structures to availability and utilization of plant tissue nutrients [8]. The objective if this project was to use SR-IMS technique to study the microstructures of chickpea seed tissue within cellular dimension.

\section{Material And Methods}

\section{Chickpea Seed and SR-IMS Microspectroscopic Window Preparation}

The chickpea seeds (CDC Cory) were collected from the Crop Development Center (University of Saskatchewan, Saskatoon, SK). Chickpea seeds were frozen at $-20^{\circ} \mathrm{C}$ on the object disks in a cryostatic microtome and then were cut into thin cross-sections ( $c a .8 \mu \mathrm{m}$ thick) using a microtome at the Canadian Light Source (Saskatoon, SK). The unstained cross-section of the chickpea was rapidly transferred to a barium fluoride $\left(\mathrm{BaF}_{2}\right)$ window (size $13 \mathrm{~mm} \times 1 \mathrm{~mm}$ disk, Crystran Ltd., Poole, UK) for microspectroscopic work in transmission mode.

\section{Photomicrograph of Cross Section of Chickpea}

Photomicrographs of cross sections of the chickpea tissues were taken using a Zeiss AxioPlan microscope with a digital camera (10×20 magnification).

\section{Synchrotron Light Source and SR-IMS}

The experiment was carried out on the Mid-Infrared beamline (01B1-1) at the Canadian Light Source (Saskatoon, SK). All infrared images were obtained using the offline system: Agilent Cary 670 FTIR spectrometer (Agilent Technologies, Santa Clara, CA, USA) with a thermoelectrically-cooled deuterated Lalanine doped triglycine sulphate (DLaTGS) detector and a Cary 620 Microscope with a $128 \times 128$ Focal Plane Array detector. The spectrometer was equipped with an Attenuated Total Reflection (ATR) accessory. This configuration allows a field of view of approximately $422.4 \mu \mathrm{m} \times 422.4 \mu \mathrm{m}$ (called a tile; 
$3.3 \mu \mathrm{m} \times 3.3 \mu \mathrm{m}$ per pixel area) and the simultaneous acquisition of 16,384 spectra. Spectra were collected from the mid-infrared range from ca. $3900-800 \mathrm{~cm}^{-1}$ with 64 scans per spectrum at $4 \mathrm{~cm}^{-1}$ resolution for chickpea endosperm and wall area $(844.8 \mu \mathrm{m} \times 844.8 \mu \mathrm{m}$ for each area). Background spectra were collected on the BaF2 window with the same setting.

\section{Data Analysis and Chemical Imaging}

The collected spectra of chickpea tissue were corrected with the background spectrum, displayed in absorbance mode, and analyzed using Orange Data Mining software 3.17 [9]. A rubber band baseline correction was used to pre-process the raw spectra to generate the final spectra. The data were displayed as a spectra graph including all chemical components/functional groups and a series of spectroscopic images collected at individual wavelengths for different chemical components/functional groups. Chemical imaging of functional groups including $\mathrm{C}-\mathrm{H}$ stretch, Amide I and Amide II, C=O carbonyl, structural carbohydrates, and carbohydrates in the intrinsic microstructures of chickpea tissues were determined using the Orange Data Mining Software. Multivariate spectral analysis, principal component analysis (PCA), was performed using ggbiplot package in R software (Version 4.0.2) with the spectra region ca. $3900-800 \mathrm{~cm}^{-1}$. The PCA application in spectral analysis has been reviewed by [11].

\section{Results And Discussion}

\section{Advanced Analytical Technique (SR-IMS)}

Traditional wet chemical analysis requires homogenization of plant tissue and separation of components from the complex matrix. This processing could destroy the chemical components and molecular structures of the plant tissue thus fails to link tissue structural information to chemical information of the samples [12] . The spatial origin and distribution of the nutrients in plant tissues affect its digestibility and utilization by animals [13]. Compared to traditional chemical analysis, synchrotron radiation based technique has the advantages of being highly sensitive, high-throughput and non-destructive. It can obtain chemical information of plant tissue within a cellular dimension. However, due to the limited beamtime or machine time, this technique could not be used on field application but suited to a limited number of samples such as mutants, new breeding types, and overexpressing lines [14]. Increase in the capability of beamline, scanning systems, and detectors would further improve its spatial resolution and capability.

\section{Photomicrograph of Cross Section}

The photomicrographs (Figure 1 and Figure 2) present the intrinsic structure of endosperm tissue and wall tissue of the chickpea seed (ca. $8 \mu \mathrm{m}$ cross-section). The starch granules can be clearly seen in both Figures. On Figure 2, the pericarp (outside of the seed coat) was not shown because it got separated easily from the seed during cutting. No specific chemical information on chickpea micro tissue can be obtained through such images. 


\section{SR-IMS Spectral Analysis}

When infrared radiation passes through a sample, it produces a spectrum representing the molecular absorption/transmission which creates a molecular fingerprint of the sample [15]. A major application of infrared spectroscopy is to identify molecular functional groups based on the spectra. In complex plant tissues, each functional group has specific molecular structure and its unique conformation produces its own specific infrared spectrum [6]. The mid-infrared (mid-IR) spectrum within $4000-800 \mathrm{~cm}-1$ is often used as a tool to detect molecular structures of different biopolymers. In plant, the main components include protein, lipid, nonstructural carbohydrates (mainly starch), and structural carbohydrates (cellulose, hemicellulose, and lignin). All these components or corresponding functional groups have specific spectral features in the mid-IR region [16].

In this study, we collected 65536 spectra for each area $(844.8 \mu \mathrm{m} \times 844.8 \mu \mathrm{m})$. Both spectra graphs from the endosperm and wall showed the peaks for $\mathrm{N}-\mathrm{H}$ and $\mathrm{O}-\mathrm{H}$ stretch, $\mathrm{C}-\mathrm{H}$ stretch, $\mathrm{C}=\mathrm{O}$ carbonyl group, Amide I and Amide II, structural carbohydrates, and carbohydrates (Figure 3 and 5). The two spectra graphs had similar patterns but not the exactly the same due to the different intrinsic structures between endosperm and wall of the seed. The color maps of functional groups were presented in Figure 4 and Figure 6. Each color map shows an area of $844.8 \mu \mathrm{m} \times 844.8 \mu \mathrm{m}$ with $256 \times 256$ pixels and a single pixel spectrum measuring an area as small as $3.3 \mu \mathrm{m} \times 3.3 \mu \mathrm{m}$ of the sample tissue.

Figure 4A and Figure 6A show the integrated area which indicate total carbohydrates concentration and distribution. The ruler on the right of each image shows the chemical intensity of the corresponding composition or functional group. This region includes both structural and nonstructural carbohydrates [13]. There were three peaks in this region centered at ca. 1143, 1079, 1022, and $933 \mathrm{~cm}^{-1}$. Figure $4 \mathrm{~A}$ shows carbohydrate spatial distribution with higher intensity which mainly includes starch in the endosperm compared to wall.

Plant cell walls have the most cellulose and hemicellulose components. Figure 4B and Figure 6B show the structural carbohydrates which are mainly associated with hemicellulose and cellulose compounds [4]. Cellulosic compounds include phenolic-carbohydrate complex, hemicellulose encrustation, and cellulose crystallinity [17]. There are four peaks visible in this region centered at ca. 1447, 1405, 1342, and $1242 \mathrm{~cm}^{-1}$, respectively.

Figure 4C and Figure 6C show the areas under the ca. $1650 \mathrm{~cm}^{-1}$ peak (Amide I peak) and $1550 \mathrm{~cm}^{-1}$ peak (Amide II peak) attributed to absorption of protein. The amide I and amide II are indicators of the protein area in the sample and they are characterized by $\mathrm{C}=\mathrm{O}$ and $\mathrm{N}-\mathrm{H}$ bonds [18]. Both figures show that protein distribution in endosperm and wall are not even.

Figure 4D and Figure 6D show the area under the $1735 \mathrm{~cm}^{-1}$ peak. This band indicates the carbonyl group $(C=0)$ stretching vibration in ester linkage which is the main structure of this band [6]. The lipid concentration in both endosperm and wall is low based on the intensity ruler. 
Figure $4 \mathrm{E}$ and Figure $6 \mathrm{E}$ show the area of lipid microstructure. In this region, spectral characteristics of lipid-related biopolymer mainly include $\mathrm{CH}_{3}$ asymmetric, $\mathrm{CH}_{2}$ asymmetric, $\mathrm{CH}_{3}$ symmetric, and $\mathrm{CH}_{3}$ symmetric stretching bands [19]. The intensity of lipid related molecular structure is higher in the endosperm compared to that in the wall area.

The above work shows that chemical imaging of functional groups and their distribution across chickpea tissue within a cellular level can be accomplished using the Infrared microspectroscopy powered by the bright synchrotron light. SR-IMS was used to examine the inherent molecular structure features of frost damaged wheat and the author found that the climate conditions did affect the structural characterization of wheat [20]. The multivariate PCA analysis classifies and visualizes the overall difference in the inherent molecular structures between endosperm and wall tissue of chickpea and the plot is presented in Figure 7. The first two principal components (PC) explained $48 \%$ and $29.6 \%$ of the variations in the molecular spectral data set, respectively. The endosperm spectra can be clearly separated from the wall spectra by the PC1 which accounted for $48 \%$ of the variance. The chemical structural and spectroscopic information of chickpea obtained from SR-IMS would be beneficial for better and effective utilization of chickpea breeding and processing. Using the synchrotron based technique will bring a new level of understanding and analytical information on molecular intrinsic structure in chickpea, thus increasing the fundamental understanding of molecular structural matrix within cellular dimension which are related to nutrient delivery and nutrient utilization [8].

\section{Conclusions}

The SR-IMS could be used to map intrinsic structure of chickpea tissue in pixel-sized increments (3.3 $\mu \mathrm{m})$ and observe chickpea tissue within a cellular level. The results showed that with SR-IMS, the distribution of chemical components/functional groups such as protein, lipid, and carbohydrates could be imaged. Such spectroscopic information on intrinsic molecular structure can be used for selecting superior variety of chickpea as well as prediction of chickpea nutritive value for human and animals.

\section{Abbreviations}

SR-IMS: synchrotron radiation-based infrared microspectroscopy; $\mathrm{BaF}_{2}$ : barium fluoride; DLaTGS: deuterated L-alanine doped triglycine sulphate; ATR: Attenuated Total Reflection; PCA: principal component analysis; PC: principal component

\section{Declarations}

\section{Acknowledgements}

The authors are grateful to Chithra Karunakaran (Canadian Light Source, Canada) for her technical support.

\section{Authors' contributions}


XF and NL conceived and designed the study; XF conducted the experiment, analyzed the data, and wrote the manuscript; PY supervised the project and reviewed the manuscript.

\section{Funding}

The funding support from Ministry of Agriculture Strategic Research Chair (PY) Program fund, the Natural Sciences and Engineering Research Council of Canada (NSERC-Individual Discovery Grants and NSERCCRD Grants), the Agriculture Strategic Research Chair Program Fund, the Saskatchewan Pulse Growers (SPG), the Prairie Oat Growers Association (POGA), the SaskCanola, the Agricultural Development Fund (ADF), the SaskMilk, the Saskatchewan Forage Network (SNK), the Western Grain Research Foundation (WGRF), Guangdong Basic and Applied Basic Research Foundation (2019A1515110780), and the partial PDF fellowship (to Xin Feng) under the Misiwêskamik International Postdoctoral Fellowship from the University of Saskatchewan are acknowledged.

\section{Availability of data and materials}

All data generated or analysed during this study are available from the corresponding author by request. The datasets supporting the conclusions of this article are included in the article

\section{Ethics approval and consent to participate}

Not applicable.

\section{Consent for publication}

Not applicable.

\section{Competing interest}

The authors declare that they have no competing interests.

\section{References}

1. Singh, N, KS Sandhu, and M Kaur.Chracterization of starches searated forom Indian chickpea cultivars. J. Food Eng. 2004; 63: 441-9.

2. Mustafa, AF, AP Thacker, JJ McKinoon, I David, and A Christensen.Nutrional value of feed grade chickpeas for ruminants and pigs. J. Sci. Food Agric. 2000; 80: 1581-8.

3. Reed, JJ, GP Lardy, ML Bauer, TC Gillbery, and JS Caton.Effects of field pea level on intake, digestion, microbial efficiency, ruminal fermentation, and in situ disappearance in beef steers fed growing diets. J. Anim. Sci. 2004; 82: 2123-30.

4. Yu, P, H Block, Z Niu, and K Doiron. Rapid characterization of molecular chemistry and nutrient makeup and microlocalization of internal seed tissue J. Synchrotron. Rad. 2007; 14: 382-90. 
5. Abeysekara, S, NA Khan, and P Yu.Relationship between protein molecular structural makeup and metabolizable protein supply to dairy cattle from new cool-season forage corn cultivars. Acta Mol. Biomol. Spectrosc. 2018; 191: 303-14.

6. Wetzel, DL, AJ Eilert, LN Pietrzak, SS Miller, and JA Sweat.Ultraspatially-resolved synchrotron infrared microspectroscopy of plant tissue in situ. Cell Mol Biol (Noisy-le-grand). 1998; 44: 145-68.

7. Theodoridou, $\mathrm{K}, \mathrm{S}$ Vail, and $\mathrm{P}$ Yu.Explore protein molecular structure in endosperm tissues in newly developed black and yellow type canola seeds by using synchrotron-based fouier transform infrared microspectroscopy. Spectrochimica Acta Part A. . 2014; 120: 421-7.

8. Yu, PQ.Synchrotron-based microspectroscopic analysis of molecular and biopolymer structures using multivariate techniques and advanced multi-component modeling. Canadian Journal of Analytical Sciences and Spectroscopy. 2008; 53: 220-31.

9. Demsar, J, T Curk, A Erjavec, C Gorup, and T Hocevar.Orange: Data Mining Toolbox in Python. Journal of Machine Learning Research. 2013; 14: 2349-53.

10. R. Core Team. 2013. R: A language and environment for statistical computing. R Foundation for Statistical Computing, Vienna, Austria. URL http://www.R-project.org/.

11. Yu, P.Applications of hierarchical cluster analysis (CLA) and principal component analysis (PCA) in feed structure and feed molecular chemistry research, using synchrotron-based Fourier transform infrared (FTIR) microspectroscopy. J Agric Food Chem. 2005; 53: 7115-27.

12. Budevska, BO.Applications of vibrational spectroscopy in life, pharmaceutical and natural sciences. J. M. Chalmers and P. R. Griffiths, eds. Handbook of vibrational spectroscopy. Vol. 5. John Wiley and Sons, Inc., New York, NY. 2002. p. 3720-32

13. Yu, P, JJ McKinnon, CR Christensen, DA Christensen, NS Marinkovic, and LM Miller.Chemical imaging of microstructures of plant tissues within cellular dimension using synchrotron infrared microspectroscopy. J. Agric. Food Chem. 2003; 51: 6062-7.

14. Feng, $X, H$ Zhang, and $P$ Yu.X-ray fluorescence application in food, feed, and agricultural science: a critical review. Crit. Rev. Food Sci. Nutr. 2020. doi: 10.1080/10408398.2020.1776677.

15. Joe, LW and CB Roth. Infrared Spectrometry, Method of Soil Analysis, Part 1. Physical and Mineralogical Methods, 2nd ed.; Agronomy Monograph 9; Amercian Society of Agronomy-Soil Science Society of America: Madison, WI. 1986;

16. Tanino, K, R Willick, K Hamilton, P Vijayan, Y Jiang, GS Brar, P Yu, L Kalcsits, R Lahlali, B Smith, DB Fowler, R Kutcher, R Bueckert, T Warkentin, and C Karunakaran.Chemotyping using synchrotron midinfrared and X-ray spectroscopy to improve agricultural production. Canadian Journal of Plant Science. 2017; 97: 982-96.

17. liyama, $K$ and TBT Lam.Structural characteristics of cell walls of forage grasses-their nutritional evaluation for ruminants- review. Asian-Aust. J. Anim. Sci. 2001; 14: 862-79.

18. Marinkovic, NS, R Huang, P Bromberg, M Sullivan, J Toomey, LM Miller, E Sperber, S Moshe, KW Jones, E Chouparova, S Lappi, F S., and MR Chance. Center for Synchrotron Biosciences' U2B 
beamline: an international resource for biological infrared spectroscopy. J. Synchrotron Radiat. . 2002; 9: 189-97.

19. Xin, $\mathrm{H}$ and $\mathrm{P}$ Yu.Detect changes in lipid-related structure of brown- and yellow-seeded Brassica Carinata seed during rumen fermentation in relation to basic chemical profile using ATR-FT/IR molecular spectroscopy with chemometrics. Spectrochim Acta A Mol Biomol Spectrosc. 2014; 133: 811-7.

20. Xin, $\mathrm{H}, \mathrm{X}$ Zhang, and $\mathrm{P}$ Yi.Using synchrotron radiation-based infrared microspectroscopy to reveal microchemical structure characterization: frost damaged wheat vs. normal wheat. Int. J. Mol. Sci. 2013; 14: 16706-18.

\section{Figures}

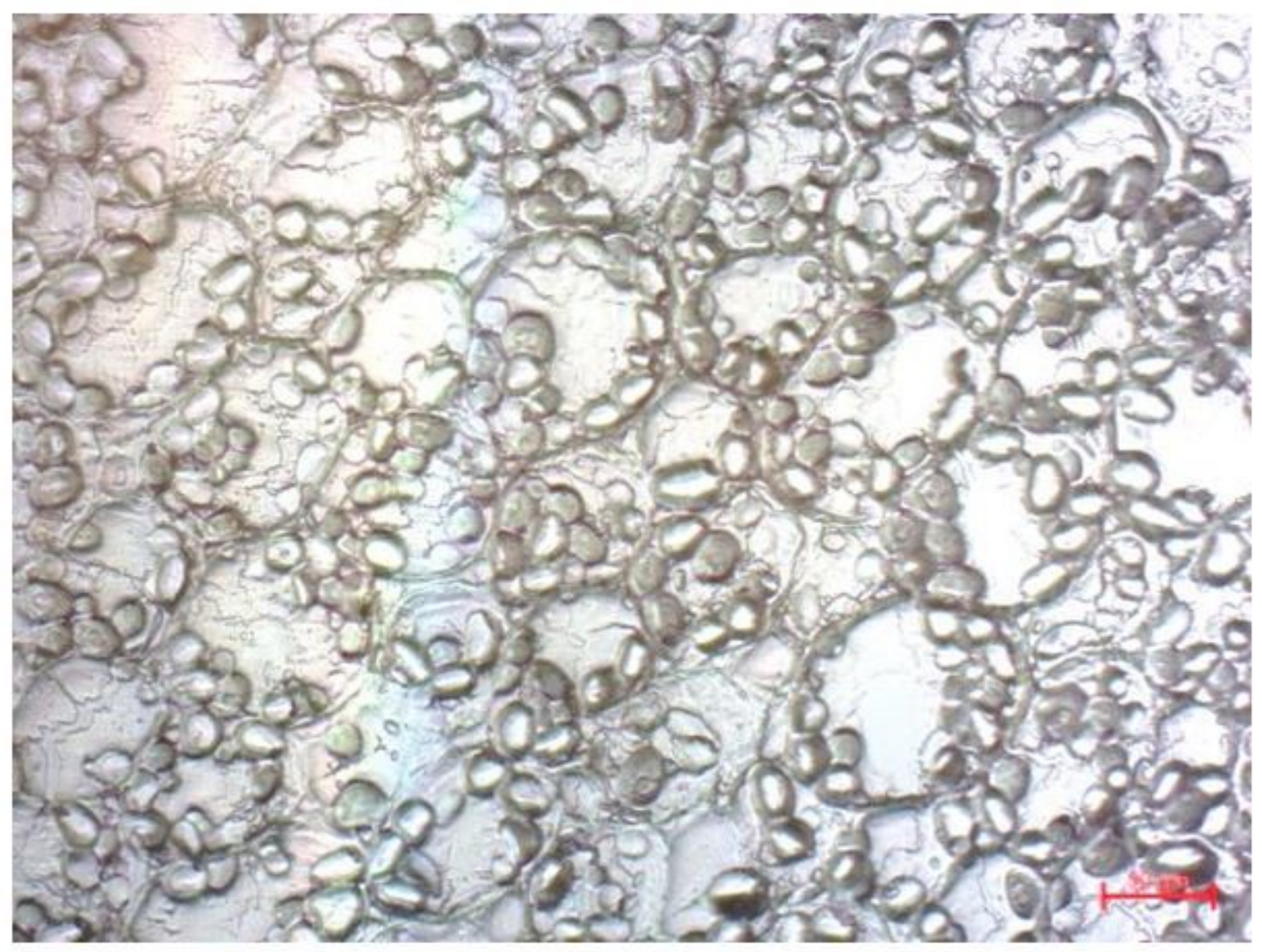

\section{Figure 1}

Photomicrograph of cross section of chickpea (CDC Cory) showing the intrinsic structure of endosperm (magnification, $10 \times 20$ ). 


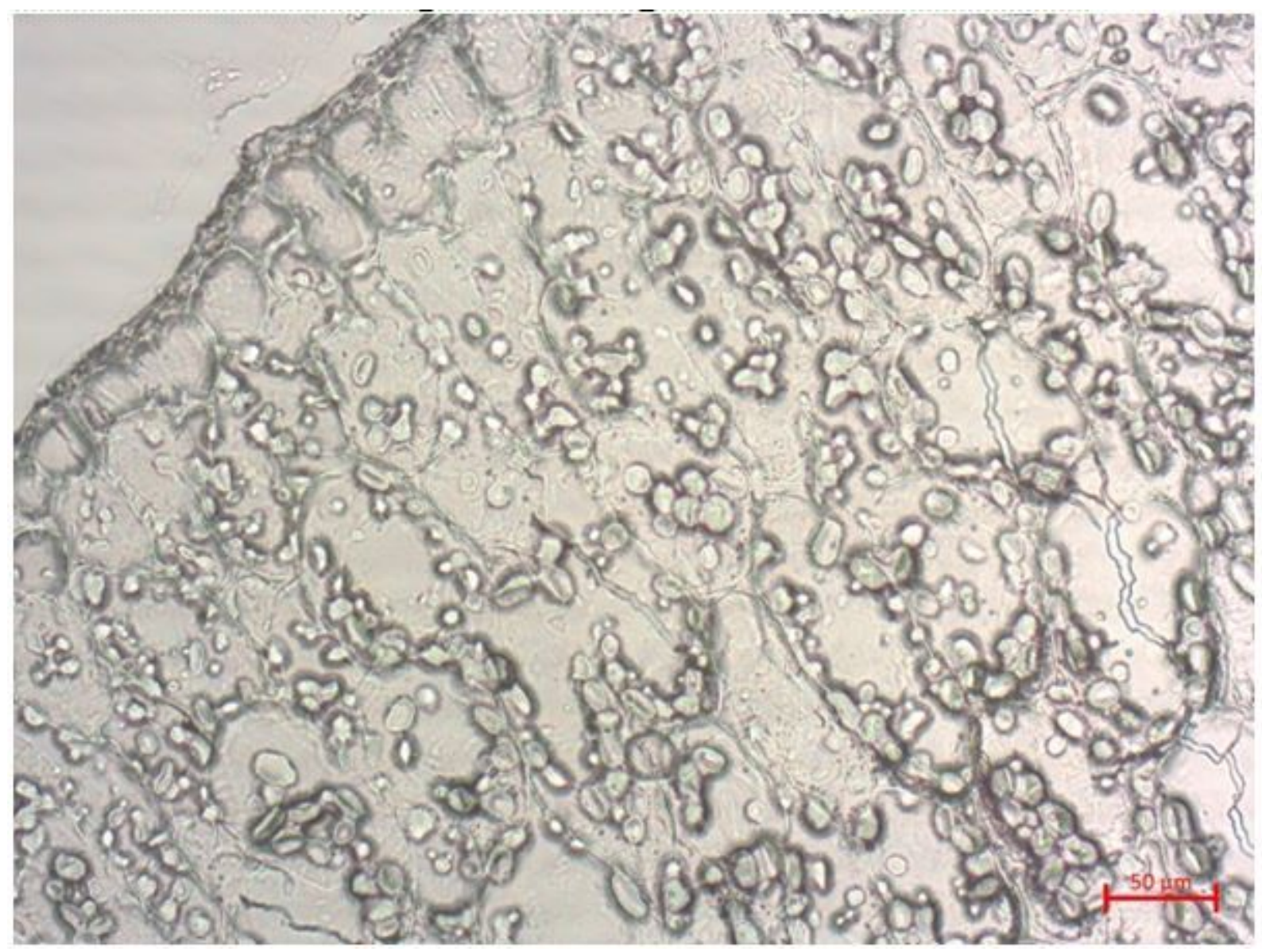

Figure 2

Photomicrograph of cross section of chickpea (CDC Cory) showing the intrinsic structure of wall area (magnification, 10×20). 


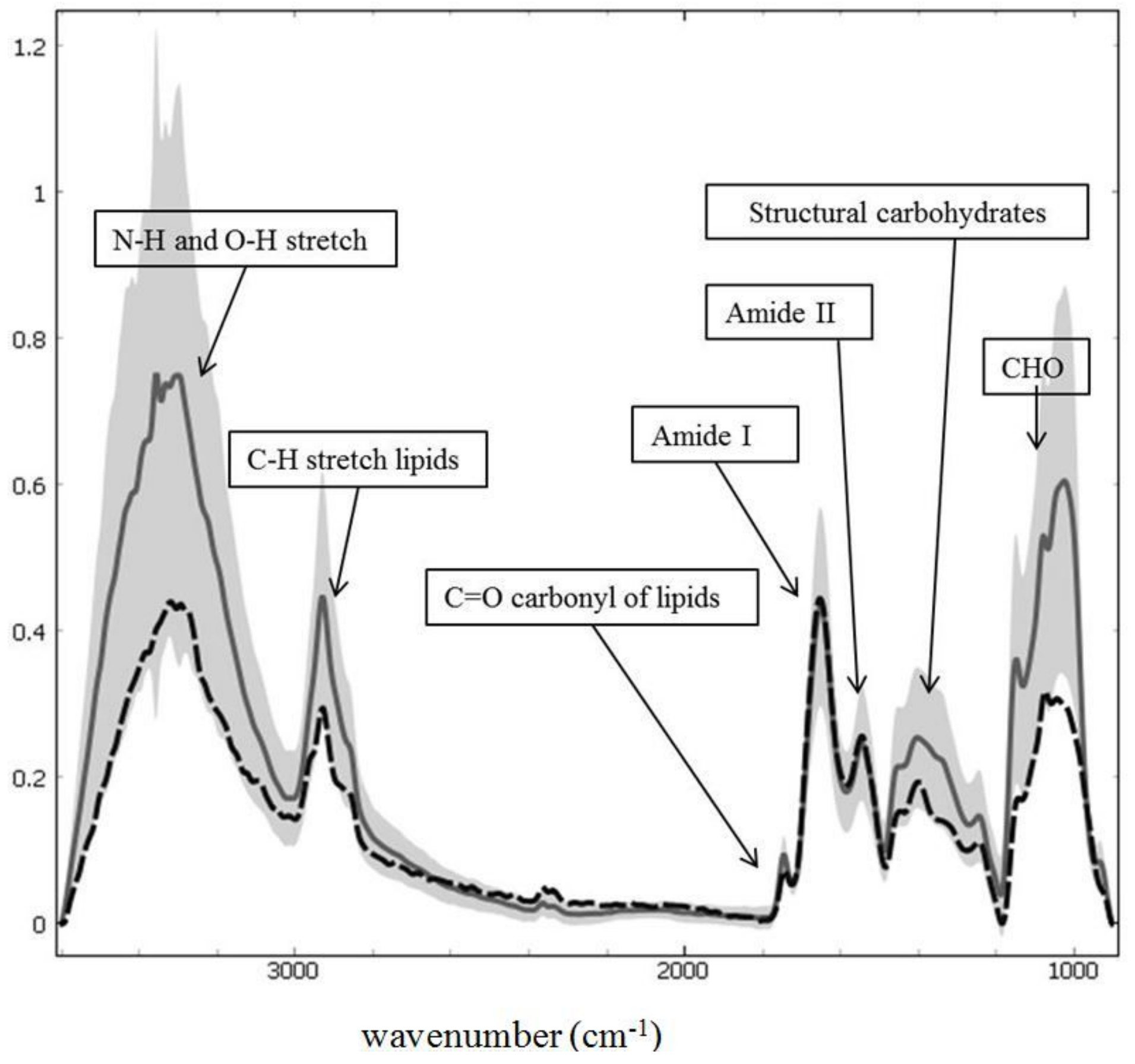

Figure 3

The spectra graph from the endosperm area of raw chickpea seed (CDC Cory). 


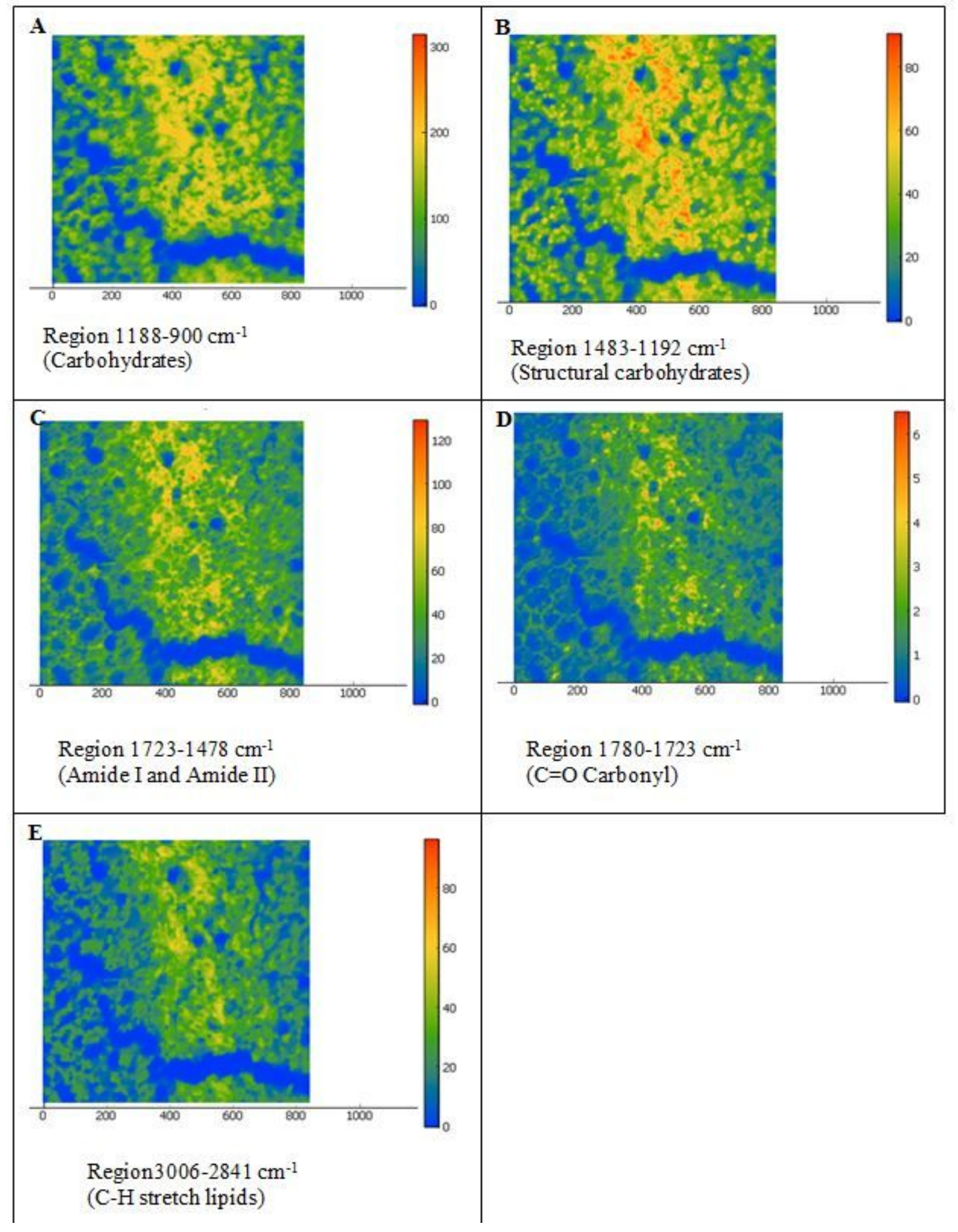

Figure 4

The imaging graph from the endosperm tissue of chickpea seed (CDC Cory). 


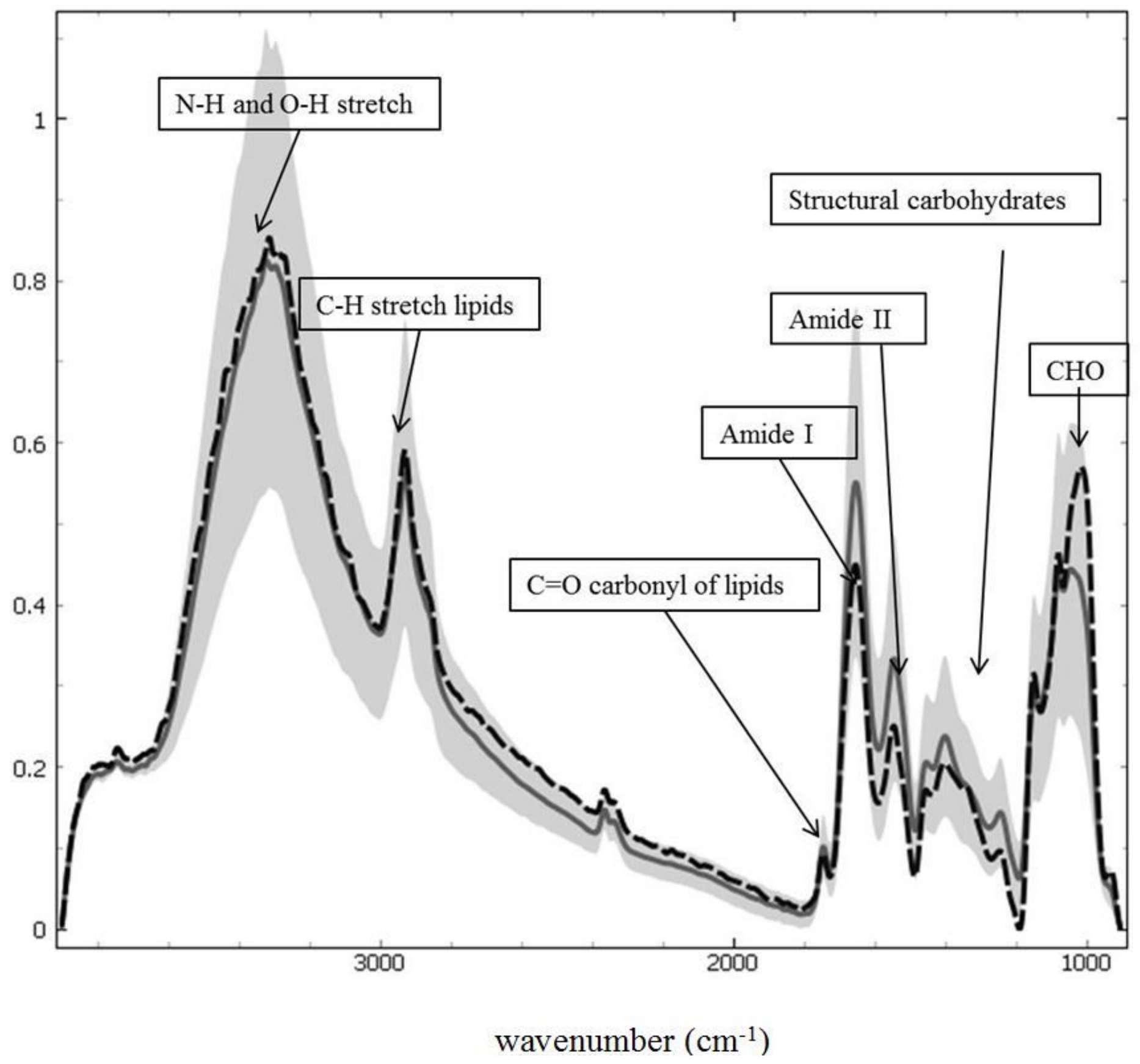

Figure 5

The spectra graph from the wall area of raw chickpea seed (CDC Cory). 


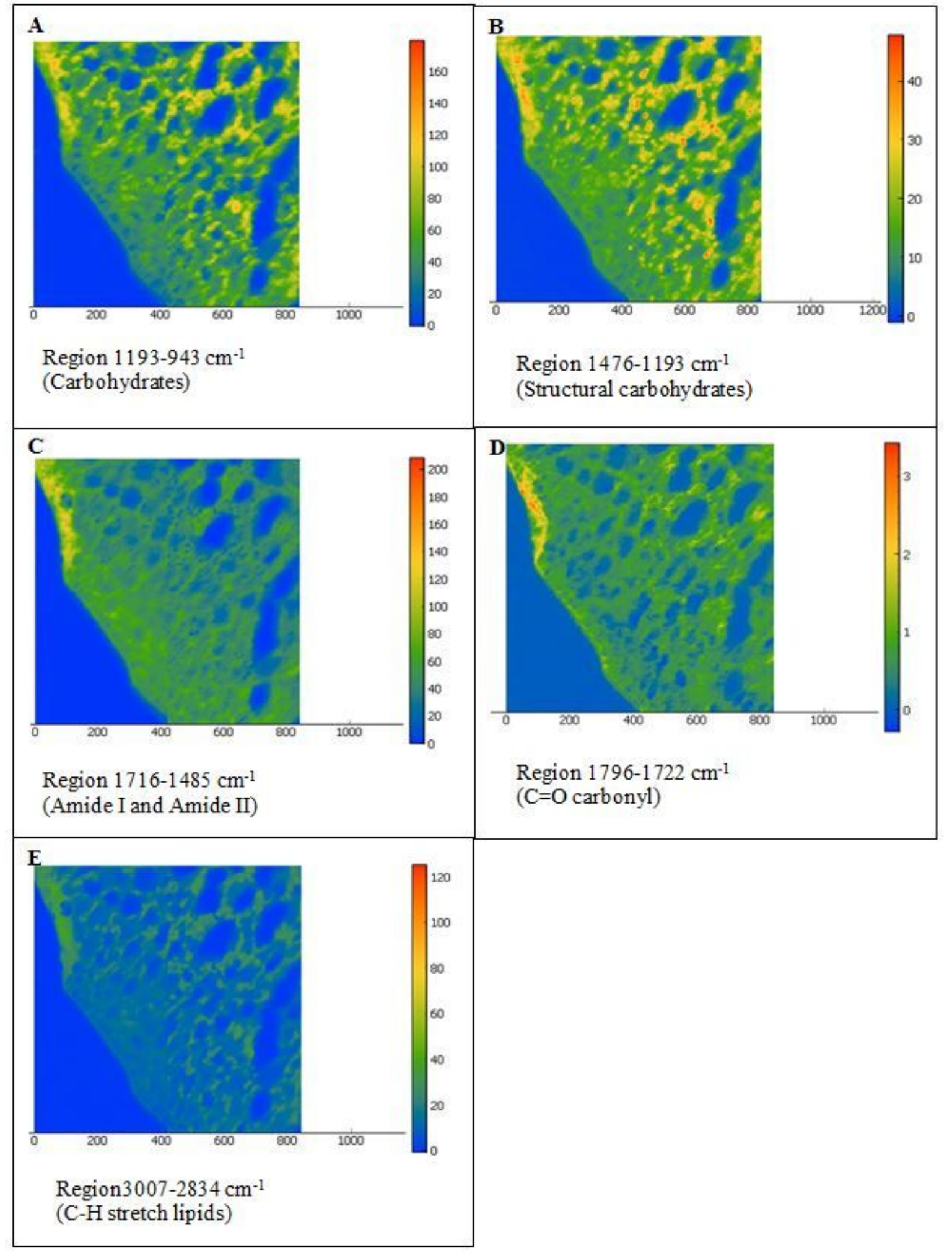

Figure 6

The imaging graph from the wall area of chickpea seed (CDC Cory). 


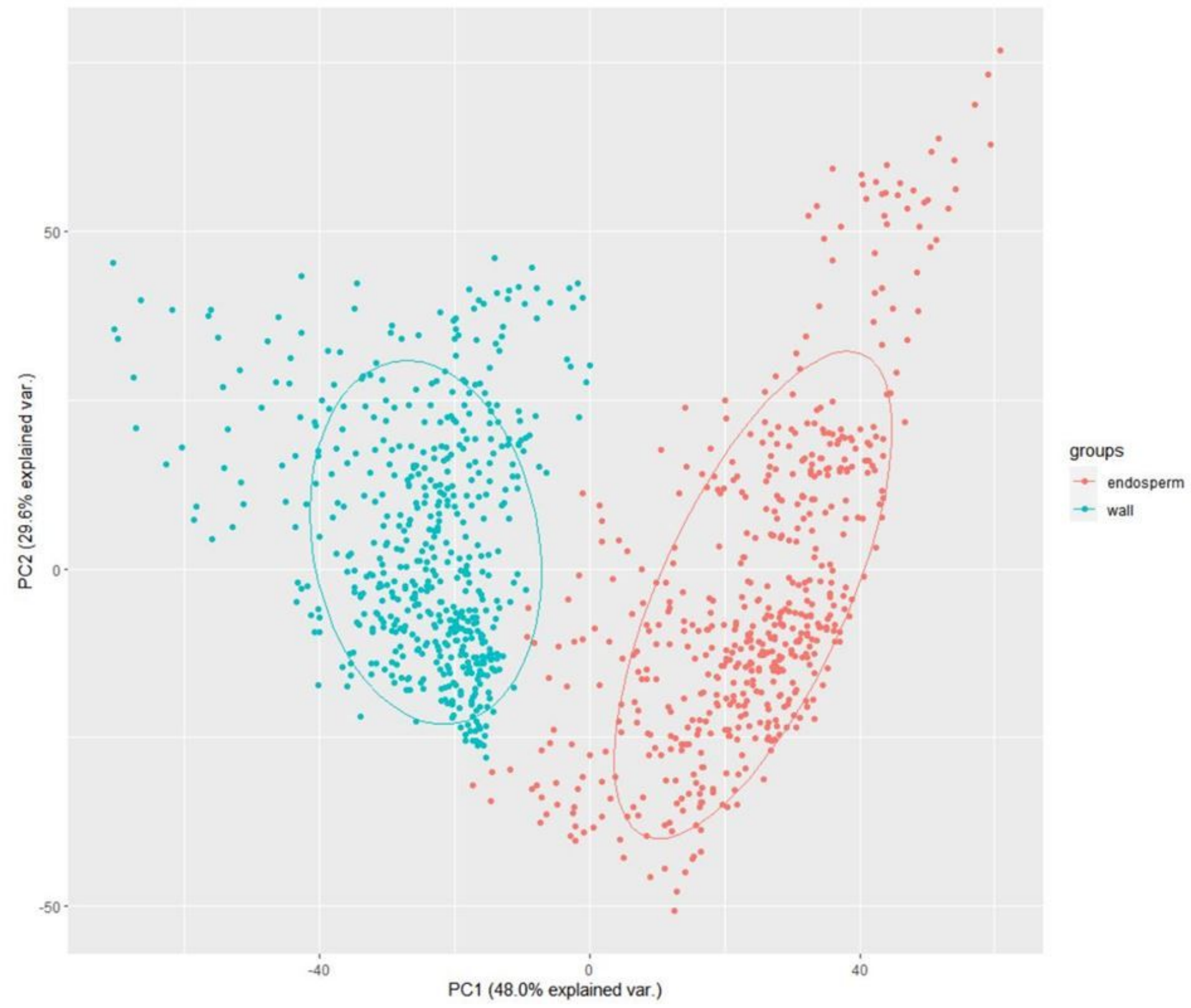

Figure 7

Multivariate spectral analysis of principal component analysis (PCA) plot of the spectral data from the mid-infrared region (ca. 3900-800 cm-1) representing the overall difference in overall molecular structures in the endosperm tissue and wall tissue of chickpea. 